\title{
Assessment of Nutritional Status of Children with Special Needs
}

\author{
Eman T. Farha ${ }^{1}$, Fatma A. El-Esrigy ${ }^{2}$, Taghreed M. Farhat ${ }^{2}$, Nahla M. Said ${ }^{2}$ \\ ${ }^{1}$ Primary Health care Unit, Berket El-Sabae, Ministry of Health, Menoufia, Egypt. \\ ${ }^{2}$ Family Medicine department, Faculty of Medicine, Menoufia University, Menoufia, Egypt.
}

\begin{abstract}
:
Background: Nutrition for the children with special needs is a complex concern where the altered nutritional needs, physical problems, and behavioral issues are the sequence of reciprocal causes that influence each other. Objective: This study aimed to assess the nutritional status of the children with special needs based on anthropometric measures and hemoglobin $(\mathrm{Hb})$ levels. Methods: This cross-sectional study enrolled 208 children (aged from 6 to 14 years old, 92 males and 116 females) from 2 special needs children schools in Menoufia Governorate, Egypt. The included children were classified into 2 age groups $(6-<11$ years old) and (11- $\leq 14$ years old). Sociodemographic history, type of disability, weight of mother at delivery were obtained from the caregivers. The nutritional status of the studied children was evaluated based on anthropometric measurements according to standard WHO Z scoring procedures and $\mathrm{Hb}$ levels $(\mathrm{g} / \mathrm{dl})$. Results: Down syndrome represented the highest proportion of the studied participants $(23.3 \%)$, followed by ADHD (16.3\%). In accordance with the WHO child growth standard, $16.3 \%$ of the studied children were underweight and $46.2 \%$ were severely stunted. Regarding BMI, $24 \%$ of the participants were at risk for overweight, $11.5 \%$ were at risk for obesity, and $7.7 \%$ were severely wasted. There was a high statistically significant difference between type of disability and BMI. Moreover, a statistically significant difference was found between BMI, socioeconomic status, and mother's weight at delivery. Besides, the mean $\mathrm{Hb}$ level was significantly lower in underweight females in the $11-\leq 14$ years old age group. Conclusion. Malnutrition is a prevalent problem in children with special needs. Type of disability, socioeconomic status, and mother's weight during pregnancy are strongly related to malnutrition in these children.
\end{abstract}

Keywords: Anthropometric measurement, Children of special needs, Malnutrition, Z scoring

\section{Introduction:}

Children with special health care needs $(\mathrm{CSHCN})$ are defined as: "Children with or at increased risk for a developmental, chronic, physical, behavioral, or emotional condition and who also require more health and related services beyond those required for children generally". ${ }^{(1)}$

In a community-based Egyptian survey, the prevalence of children with special needs was estimated to be $12.2 \%$. Among these children, the most prominent conditions requiring special health care are sensory and cognitive impairments as well as impaired mobility. ${ }^{(2)}$

Inadequate nutrition is a disabilityrelated problem for many children in the developing countries, manifested as lack of growth or stunting. The scope of this problem is substantial, with at least $30 \%$ of children under the age of five years old reported being moderately or severely stunted. ${ }^{(3)}$

Children with special needs are particularly vulnerable to poor growth due to developmental delays and lack of interest 
in food. In addition, some conditions cause an increase in the metabolism. For example, some children with cerebral palsy have frequent muscle spasms that burn calories. Other children may be determined to consume only one type of food every day which possibly leads to nutrient deficiencies. $^{(4)}$

Children with special needs are not only at risk for underweight and difficult feeding, but are also at risk for overweight. For example, children with Down's syndrome tend to be heavier than other children due to low muscle tone, rejection of healthier or low-calorie foods, and bone problems that may limit their physical activity. In addition, children with conditions leading to using a wheelchair are at risk for overweight due to the lack of physical activity. ${ }^{(5)}$

The family physician's role is to help the family navigate sub-specialty visits and consultations, advocate for school and home services, and cope with the emotional stress of caring for a child with special needs. $^{(6)}$ Moreover, similar to other developing countries, the nutritional care in Egypt for the children with special needs is not well established. Therefore, the aim of this study was to assess the nutritional status of children with special needs on the basis of anthropometric and hemoglobin $(\mathrm{Hb})$ measures.

\section{Subjects and methods:}

This cross sectional study enrolled 208 children with special needs aging from 6 to 14 years old (92 males and 116 females) in Shebeen El-Kom and Berket EL-Sabaa schools for children with special needs, Menoufia governorate, Egypt, from 1 February 2018 till the end of May 2019.

Both schools were selected randomly among 18 schools for children with special needs in 9 districts in Menoufia governorate, Egypt. The total target population was 1864 . The sample size was calculated using the online Rao soft program based on the proportion of the target population which was $19.8 \%$. ${ }^{(7)}$ The calculated sample size was 158 and increased to 208 for non-response. A purposive sample was used.

The children with special needs were categorized by the school administration on the basis of intelligence quotient (IQ), regardless of their age, into 6 classes in the primary stage and 3 classes in the intermediate stage in both Shebeen El-Kom and Berket EL-Sabaa schools. Each class included about 30 children.

The children who were uncooperative, refused blood sampling, had chronic diseases as congenital heart defects, diabetes mellitus, and neurological diseases i.e. convulsions and seizures, history of 
heart and brain surgery, suffering from frequent vomiting and frequent diarrhea, do not have available family health record in family health units/centers to which these schools are affiliated were excluded from the study.

The overall target for children in both schools was $257 \quad(20$ students were excluded in the pilot phase and 27 met the exclusion criteria), 208 children have been recruited with a response rate of $80.9 \%$.

The included children in this study were classified into 2 age groups; $(6-<11$ years old) group and (11- $\leq 14$ years old) group according to the cutoff age of adolescent defined by WHO. ${ }^{(8)}$

\section{Data collection technique:}

The socio-demographic data based on the Fahmy et al. (9) questionnaire, in addition to the type of special needs (SN), a complete medical and family history, especially for genetic diseases, were collected through interviews with the caregivers in the medical clinics of both schools. Data about the mother's body weight at delivery were obtained from the family health records in the family health units/centers to which these schools are affiliated.

\section{Anthropometric Measurement:}

Weight (kilogram) and height (centimeter) of the children were measured in accordance with standard WHO procedures. The weight-for-age (WAZ), weight-for-height (WHZ) and height-forage (HAZ) scores were calculated using the anthropometric calculator module WHO Anthro plus children's software 5-19 years old. ${ }^{(10)}$

According to the WHO Global Child Growth and Malnutrition Database, moderate underweight was defined as a cutoff $\mathrm{Z}$ score of $<-2$ low WAZ, stunting as a cut-off $\mathrm{Z}$ score of $<-2$ low HAZ, and wasting as a cut-off $\mathrm{Z}$ score of $<-2$ low WHZ, while the Z score $<-3$ SD was used to define severe malnutrition. Overweight: $>+1 \mathrm{SD}$ (equivalent to BMI $25 \mathrm{~kg} / \mathrm{m} 2$ at 19 years old), obesity: >+2SD (equivalent to BMI $30 \mathrm{~kg} / \mathrm{m} 2$ at 19 years old), thinness: <2 SD, severe thinness: <-3SD. Then, the included subjects were classified according to BMI Z scores where the score $<-2$ indicates underweight, -2 indicates normal weight and >2 indicates overweight. ${ }^{(11)}$

\section{Biochemical measurements:}

Blood samples were collected by the researcher from target subjects with the cooperation of the school's administrative staff and nurse then transferred to the selected laboratory for measuring hemoglobin concentrations (208 samples). Anemia is defined as the hemoglobin level of two standard deviations below the mean $(13.5 \mathrm{~g} / \mathrm{dl})$ for the age range of 6-12 years. When the children are 12 years old, the 
standard of hemoglobin can be further divided into gender-specific ranges (14.5 $\mathrm{g} / \mathrm{dl}$ vs. $14 \mathrm{~g} / \mathrm{dl}$ for males and females, respectively). ${ }^{(12)}$

Pilot study: A pilot study was done to measure the feasibility of the study setting, content, and validity of the tools used on a convenient sample of 20 subjects who accepted and were then excluded from the study.

Ethical considerations: The study was approved by the Ethical Committee of Faculty of Medicine, University of Menoufia, Egypt. Administrative permissions have been obtained from the Faculty of Medicine. Verbal consent was obtained from all participants with the assurance that the information obtained are confidential.

Statistical Analysis: Data were analyzed using the Social Science Statistical Package (SSPS) version 23 (using the IBM personal computer). Quantitative data (age) were expressed as mean and standard deviations $(\mathrm{X} \pm \mathrm{SD})$ and analyzed in the Mann Whitney test. Qualitative data were expressed as numbers and percentages and analyzed using the Chi-square test.

\section{Results:}

Among the 208 included children, 44 children $(21.15 \%)$ had Down's syndrome, 26 had auditory disorders (12.5\%), 26 had attention deficit hyperactivity activity disorder (ADHD) (12.5\%), 22 had autism (10.58\%), and 18 children has mental retardation $(8.65 \%)$. While only 16 children had visual disorders $(5.77 \%), 12$ had dumbness $(3.86 \%)$, and 8 children has dwarfism (2.88\%) (Table 1).

There is Skewness of WAZ curve to the left as 34 children $(16.3 \%)$ of the studied sample for different age groups were underweight (below -2) and 14 (6.7\%) were severely underweight (below -2), with a mean weight $\mathrm{Z}$ scoring of $-0.5 \pm 1.1$ (Figure $1)$.

Also, there is Skewness of HAZ curve to the left as 60 children $(28.8 \%)$ of the studied sample for different age groups were stunted (below -2) and 96 were severely stunted (46.2\%) (below -3), with a mean height $\mathrm{Z}$ scoring of $-0.54 \pm 0.09$ (Figure 1A).

Moreover, there is Skewness of the curve to the right. Around 50 children of the studied sample (24\%) for different age groups were at risk for overweight, 24 were obese $(11.5 \%)$, and 16 children were severely wasted (7.7\%), with a mean BMI $\mathrm{Z}$ scoring of $1.46 \pm 1.05$ (Figure $1 \mathrm{~B}$ ).

A total number of 32 students of the studied sample (15.4\%) had BMI score less than 2, 30 students (14.4\%) had BMI score more than two, and $146(70.2 \%)$ with BMI score ranging from $>2$ to $<-2$ (Figure $1 \mathrm{C}$ ). 
Table 1 illustrated that the most prevalent disability in the studied subjects was down syndrome $(23.1 \%)$, followed by ADHD (16.3\%). Based on BMI z scoring, there was statistically significant difference between the type of SN and BMI in both males and females ( $p$ value <0.05) where the highest proportion of overweight subjects was among males and females with down syndrome $(64.3 \%$ and $68.7 \%$, respectively) in contrast to $(23.1 \%$ and $35 \%$, respectively) for underweight males and females with ADHD.

Table 2 demonstrated no statistically significant difference between males and females in both age groups in terms of weight for age, length for age, and BMI Z score (P. Value>0.05) (Table 2). This table also denoted that the mean $\mathrm{Hb}$ level was statistically lower in underweight females aged from $\geq 11$ - 14 years old ( $p$ value $<0.05)$.

Table (3) shows that there was a statistically significant difference between the studied groups in terms of socioeconomic status and mother's weight at delivery ( $\mathrm{p}$ value $<0.05)$ where $(50 \%$ vs $46.9 \%$ ) of the studied underweight children had low socioeconomic status and their mothers were underweight at the time of delivery.

\section{Discussion:}

A disabled child needs proper nutritional care as much as, if not more than, a normal child. Malnutrition can potentially lead to further morbidity in a child. ${ }^{(13)}$

The current study reported that the most prevalent disability was Down's syndrome, followed by ADHD; the highest proportion of overweight subjects was among males and females with down syndrome which may be contributed to low muscle tone, rejection of healthier or low-calorie foods, and bone problems that may limit physical activity in these children. While the highest proportion of underweight subjects among males and females was the ADHD children which may be explained by the excessive movement and lack of attention of these children.

Shabayek, (8) in an Egyptian study found that based on BMI for age, the high incidence of obesity was among Down's syndrome and mentally retarded females as well as autistic males compared to a high proportion of females with mental retardation and autism.

The current study indicated the left skewness of the growth curves. Compared to the WHO child growth standard, $15.4 \%$ vs. $14.4 \%$ of the study subjects had BMI scores less and more than two, respectively. In addition, there was an insignificant relationship between sex, age, WAZ, HAZ, and BAZ scores. 
This is consistent with Abd Allah et al. (14) study who found that the prevalence of underweight children (Wt / $\mathrm{A}<-2 \mathrm{SD}$ ) among the mentally retarded Egyptian subjects was $14.1 \%$, overweight children $(\mathrm{Wt} / \mathrm{A}>+2 \mathrm{SD}$ ) was $6.7 \%$, and the overall prevalence of stunting was $33.5 \%$. No significant difference was detected between age and sex.

These results are inconsistent with those of Vanagondi et al. ${ }^{(15)}$ in their Indian study who reported that about two-thirds of the children with intellectual disability had a BMI <5th percentile and about one-third of children had normal BMI in the 5th-85th percentile range.

Neyestani et al. ${ }^{(16)}$ also found that more than $70 \%$ of disabled children were below the 3rd percentile. However, $\mathrm{z}$-score for height indicated that over $42 \%$ of the disabled children were of low age. Also, authors of this study found that stunting was more prevalent in girls than in boys $(46.3 \%$ vs. $38.5 \%$, respectively). The prevalence of stunting in physicallydisabled children in Meshed was higher than in the other two cities. Disabled children in Tehran have shown the highest prevalence of low weight. These variations may be attributed to the difference in sociocultural status, type of the included disabled children, or the standard tool used to evaluate anthropometric measures.
The present study revealed that the low socioeconomic status and mother's weight at the time of delivery are significantly related to low BMI of the included children.

Alkerwi et al. ${ }^{(17)}$ clarified that the most important demographic and socioeconomic circumstances independently associated with diet quality (as indicated by healthy choices and adherence to dietary guidelines) were age, sex, country of birth, and education level.

Celhay et al. ${ }^{(18)}$ found large disparities in child nutrition indicators by socioeconomic status. A non-parametric analysis within age groups indicates that the gap between children from rich and poor families started very early in life (stunting, anemia).

This is similar to Gashaw et al. ${ }^{(19)}$ study who noted that the nutritional status of pregnant women on the basis of maternal anthropometry and biochemical profile was associated with the birth weight of their offspring. The baby born to a poorly nourished mother has a lower body weight compared to the baby of better nourished mothers.

Also, this is in line with Sharma and Mishra, (20) study who reported that both pre-pregnancy BMI and BMI were significantly associated with the infant's birth weight during pregnancy. 
The present study found that the mean $\mathrm{Hb}$ level was statistically lower in underweight females in the age group $(\geq 11$ - 14 years old). Similar results reported by Puja et al., (21) who found a significant distribution of anemia in low BMI school in Indian adolescent females which may be attributed to malnutrition and the onset of menstrual periods in girls are related to iron deficiency anemia during adolescence.

\section{Conclusions and Recommendations:}

Malnutrition is a prevalent issue for children with special needs. The type of socio-economic disability and weight of mothers during pregnancy are strongly related to malnutrition in those children.

The golden rule for malnutrition control in children with special needs includes the assessment of nutrition in the health care of those children. In addition, proper antenatal care with special emphasis on nutritional status and gradual weight gain during pregnancy is an important indicator of the proper growth and development of the fetus and, subsequently, of the infant.

\section{Study limitation:}

Difficultly in communication with children with special needs and setting meeting appointment with the caregivers. These limitation was overcome by contacting the caregivers by telephone and revising their data in the family health records.

\section{Competing interests:}

There was no conflict of interest.

\section{Funding:}

There were no funding agencies.

\section{Acknowledgment:}

The author gratefully acknowledges the support provided by the head managers of the selected schools and family health facilities.

\section{References:}

1. McPherson M, Arango P, Fox H et al. A new definition of children with special health care needs. Pediatrics. 1998 Jul 1; 102(1): 137-139.

2. Wahdan IH, El-Nimr NA. Identifying children with Special Health Care Needs in Alexandria, Egypt. Pediatric research. 2018 Jul; 84(1): 57-61.

3. UNICEF, violence against disabled children; $19^{\text {th }}$ April 2011.

4. Nzwalo H, Cliff J. Konzo: from poverty, cassava, and cyanogen intake to toxiconutritional neurological disease. PLoS neglected tropical diseases. 2011 Jun 28; 5(6):e1051.

5. Groce NE, Kerac Marko, Farkas Amy, et al. Inclusive nutrition for children and adults with disabilities The Lancet Global Health, October 2013; 1(4): e180-e181.

6. Stuart MR, Lieberman JA. The Fifteen Minute Hour: Therapeutic Talk in Primary Care. 4th ed. New York, NY: Radcliffe Publishing; 2008. 
7. WHO. WHO. Geneva, 1989 (document A42/Technical Discussions/2).

8. Shabayek MM. Assessment of the nutritional status of children with special needs in Alexandria. Part II: Anthropometric measures, The Journal of the Egyptian Public Health Association, 2004; 79(5-6): 363-382

9. Fahmy SI, Nofal LM, Shehata SF, et al. Updating indicators for scaling the socioeconomic level of families for health research. J Egyptian Public Health Assoc 2015; 90: 1-7.

10. WHO. WHO Anthro Plus for Personal Computers Manual Software for assessing growth of the world's children and adolescents, Geneva, Switzerland 2009.

11. WHO Multicentre Growth Reference Study Group. WHO child growth standards based on length/height, weight and age. Acta Paediatr Suppl. 2006; 450: 76-85.

doi:10.1080/08035320500495548)

12. Flerlage J, Engorn B, eds. The Harriet Lane Handbook: A Manual for Pediatric House Officers. 20th ed. Philadelphia, Pa.: Saunder/Elsevier; 2015: 305 .

13. Guerrant RL, Oria RB, Moore SR, et al. Malnutrition as an enteric infectious disease with long-term effects on child development. Nutr Rev. 2008; 66: 487 505.

14. AbdAllah M Asmaa, El-Sherbeny S. A. Shawkia et al. Nutritional Status of Mentally Disabled Children in Egypt. The Egyptian Journal of Hospital Medicine, 2007; 29: 604-615.

15. Vanagondi K. Kavitha, Khetavath Gopal Singh et al. Nutritional assessment in developmentally retarded children of 3-10 years age group. Int J Contemp Pediatr. 2019 Jan; 6 (1): $77-$ 81

16. Neyestani R T., Dadkhah-Piraghaj M, Haydari $\mathrm{H}$, et al. Nutritional status of the Iranian children with physical disability: a cross-sectional study. Asia Pac J Clin Nutr, 2010; 19(2): 223-230

17. Alkerwi Ala'a, Vernier Céderic, Sauvageot Nicolas et al. Demographic and socioeconomic disparity in nutrition: application of a novel Correlated Component Regression approach. BMJ Open. 2015; 5(5): e006814. doi: 10.1136/bmjopen-2014006814.

18. Celhay $\mathrm{P}$, Martinez S, Vidal $\mathrm{C}$. Measuring socioeconomic gaps in nutrition and early child development in Bolivia. Int J Equity Health 19, 122 (2020).https://doi.org/10.1186/s12939 -020-01197-1. 
19. Woldeamanuel GG, Geta TG, of Maternal Health and Nutrition on Mohammed TP et al. Effect of Birth Weight of Infant. International nutritional status of pregnant women on birth weight of newborns at Butajira Journal of Science and Research Referral Hospital, Butajira, Ethiopia. SAGE Open Med. 2019 Jan 29;7:2050312119827096. doi: 10.1177/2050312119827096. PMID: 30728970; PMCID: PMC6351719.

20. Sharma Megha, Mishra Sunita. Effects (IJSR); June 2014; 3(6): 855-858.

21. Puja Dhuppar, Suprava Patel, Rahul Maski et al. Anemia Prevalence In Adolescent School Going Girls. International Journal of Recent Scientific Research; April, 2017; 8(4): 16364-16366.
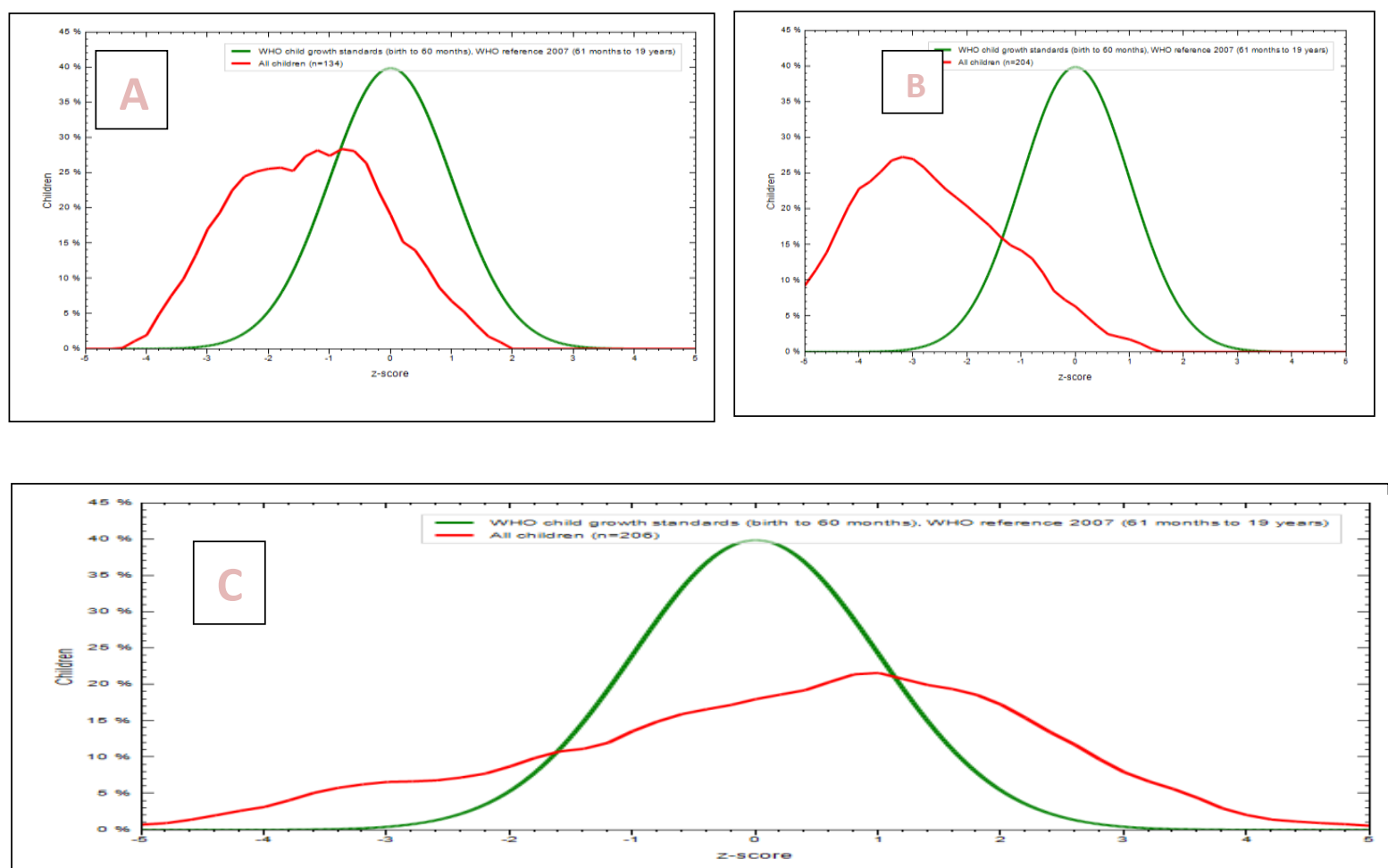

Figure (1)A: Weight-for-age z-score curve of the studied patients in comparison to the WHO standards

Figure (1)B: Height-for-age z-score curve of the studied patients in comparison to the WHO standards

Figure (1)C: BMI-for-age z-score curve of the studied patients in comparison to the WHO standards 


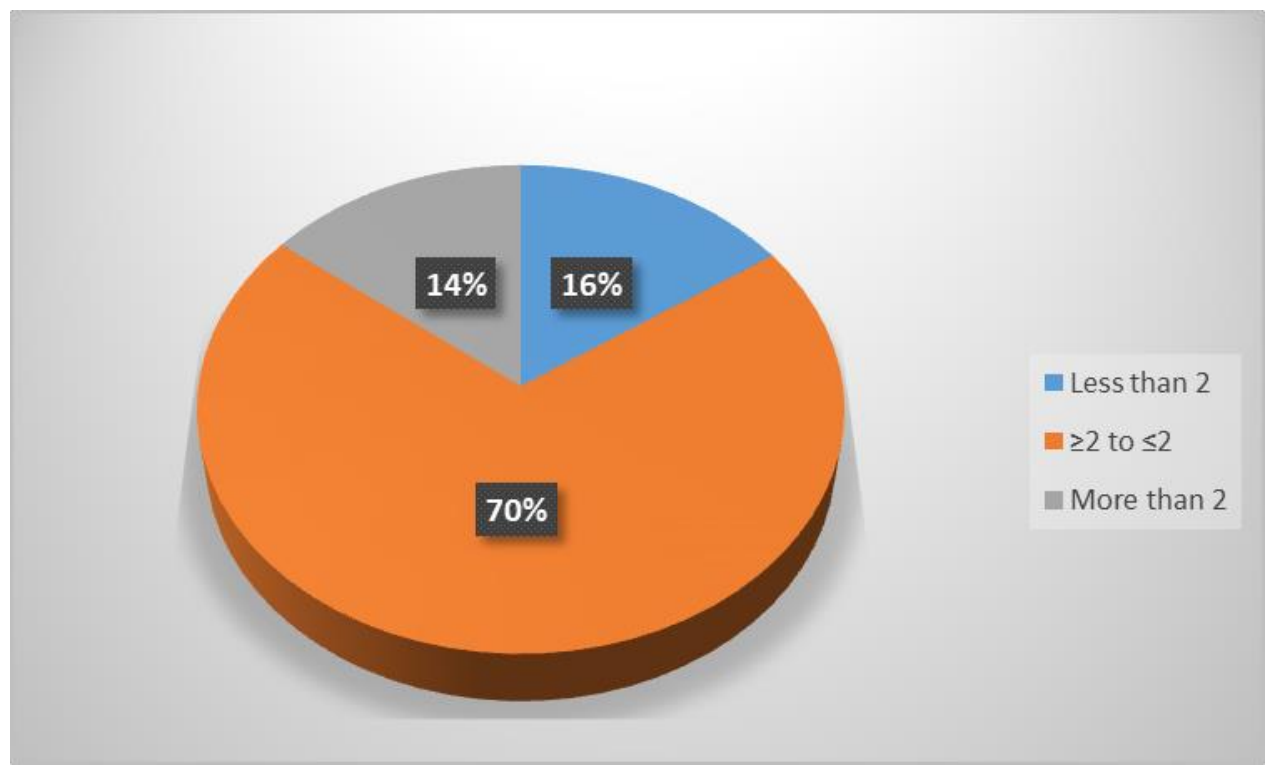

Figure (2): BMI z scoring of the studied children with special needs

Table 1: The relation between type of disability and BMI of the studied children in both genders

\begin{tabular}{|l|c|c|c|c|c|c|c|}
\hline \multirow{2}{*}{ Types of disability } & \multicolumn{3}{|c|}{ Male } & \multicolumn{3}{c|}{ Female } & $\begin{array}{c}\text { Total } \\
(208)\end{array}$ \\
\cline { 2 - 7 } & Underweight & Normal & Overweight & Underweight & Normal & Overweight & (208) \\
\cline { 2 - 7 } & No.(12) & No.(66) & No.(14) & No.(20) & No.(80) & No.(16) & No.(\%) \\
\hline - Down's syndrome & $2(16.7)$ & $13(19.7)$ & $9(64.3)$ & $3(15)$ & $10(12.5)$ & $11(68.7)$ & $48(23.1)$ \\
- Autism & $1(8.3)$ & $7(10.6)$ & $4(7.1)$ & $3(15)$ & $8(10)$ & $3(18.7)$ & $26(12.5)$ \\
- Mental retardation & $1(8.3)$ & $8(12.1)$ & $0(0)$ & $2(10)$ & $9(11.2)$ & $2(12.5)$ & $22(10.6)$ \\
- ADHD & $3(23.1)$ & $10(15.1)$ & $0(0)$ & $7(35)$ & $14(17.5)$ & $0(0)$ & $34(16.3)$ \\
- Mutism & $0(0)$ & $4(6.1)$ & $0(0)$ & $2(10)$ & $6(7.5)$ & $0(0)$ & $12(5.8)$ \\
- Dwarfism & $1(8.3)$ & $3(4.5)$ & $0(0)$ & $1(5)$ & $4(5)$ & $0(0)$ & $9(4.3)$ \\
- Visual disorders & $3(23.1)$ & $2(3)$ & $1(7.1)$ & $2(10)$ & $5(6.25)$ & $0(0)$ & $13(6.25)$ \\
- Physical impairment & $1(8.3)$ & $6(9.1)$ & $0(0)$ & $0(0)$ & $10(12.5)$ & $0(0)$ & $17(8.2)$ \\
\hline
\end{tabular}


Table (2): Anthropometric measurement and mean hemoglobin concentration (g/dl) of the studied children with special needs in different ages groups

\begin{tabular}{|c|c|c|c|c|c|c|c|c|c|c|c|c|}
\hline & \multicolumn{6}{|c|}{$6-<11$ years old } & \multicolumn{6}{|c|}{$\geq 11-14$ years old } \\
\hline & \multicolumn{2}{|c|}{ Male } & \multicolumn{2}{|c|}{ Female } & \multirow[t]{2}{*}{$\mathrm{X} 2$} & \multirow{2}{*}{$\begin{array}{c}P \\
\text { value }\end{array}$} & \multicolumn{2}{|c|}{ Male } & \multicolumn{2}{|c|}{ Female } & \multirow[t]{2}{*}{$\mathrm{X} 2$} & \multirow[t]{2}{*}{$P$ value } \\
\hline & $\begin{array}{l}\text { No. } \\
\text { (70) }\end{array}$ & $\%$ & $\begin{array}{l}\text { No. } \\
\text { (64) }\end{array}$ & $\%$ & & & $\begin{array}{l}\text { No. } \\
\text { (22) }\end{array}$ & $\%$ & $\begin{array}{l}\text { No. } \\
\text { (52) }\end{array}$ & $\%$ & & \\
\hline \multirow{2}{*}{$\begin{array}{l}\text { Weight for } \\
\text { age }\end{array}$} & \multirow{2}{*}{\multicolumn{2}{|c|}{$22.3 \pm 4.5$}} & \multirow{2}{*}{\multicolumn{2}{|c|}{$22.3 \pm 4.8$}} & \multirow[t]{2}{*}{$0.05^{*}$} & \multirow[t]{2}{*}{0.959} & \multirow{2}{*}{\multicolumn{2}{|c|}{$27.8 \pm 4.6$}} & \multirow{2}{*}{\multicolumn{2}{|c|}{$32.5 \pm 5.5$}} & T test & 0.02 \\
\hline & & & & & & & & & & & $2.4^{*}$ & \\
\hline$<-2$ & 22 & 31.4 & 18 & 28.1 & 0.087 & 0.786 & 0 & 0 & 8 & 15.4 & 2.87 & 0.238 \\
\hline$-2-2$ & 48 & 68.6 & 46 & 71.9 & & & 20 & 90.9 & 34 & 65.4 & & \\
\hline$>2$ & \multicolumn{2}{|c|}{$115.1 \pm 9.1$} & \multicolumn{2}{|c|}{\begin{tabular}{c|c}
0 & 0 \\
$116.4 \pm 8.3$
\end{tabular}} & & & \multicolumn{2}{|c|}{\begin{tabular}{c|r}
2 & 9.1 \\
$123.9 \pm 6.2$
\end{tabular}} & 10 & 19.2 & & \\
\hline \multirow{2}{*}{$\begin{array}{c}\text { Length for } \\
\text { age }\end{array}$} & \multirow{2}{*}{\multicolumn{2}{|c|}{$115.1 \pm 9.1$}} & \multirow{2}{*}{\multicolumn{2}{|c|}{$116.4 \pm 8.3$}} & \multirow[t]{2}{*}{$0.576^{*}$} & \multirow[t]{2}{*}{0.566} & \multirow{2}{*}{\multicolumn{2}{|c|}{$123.9 \pm 6.2$}} & \multirow{2}{*}{\multicolumn{2}{|c|}{$124.8 \pm 9.8$}} & \multirow{2}{*}{\begin{tabular}{|c|} 
T test \\
$0.293^{*}$
\end{tabular}} & \multirow[t]{2}{*}{0.771} \\
\hline & & & & & & & & & & & & \\
\hline$<-2$ & 48 & 68.6 & 18 & 56.3 & 1.085 & 0.298 & 18 & 81.8 & 46 & 88.5 & 0.292 & 0.589 \\
\hline$-2-2$ & 22 & 31.4 & 14 & 43.8 & & & 4 & 18.2 & 6 & 11.5 & & \\
\hline \multirow[t]{2}{*}{ BMI z score } & 16.9 & \pm 3.9 & 16. & $=4.3$ & $0.339 *$ & 0.736 & 18.1 & \pm 3.9 & 21.0 & \pm 4.3 & T test & 0.059 \\
\hline & & & & & & & & & & & $1.95^{*}$ & \\
\hline$<-2$ & 12 & 17.1 & 14 & 21.9 & 0.434 & 0.805 & 0 & 0 & 6 & 11.5 & 1.809 & 0.405 \\
\hline$-2-2$ & 46 & 65.7 & 42 & 65.6 & & & 20 & 90.9 & 38 & 73.1 & & \\
\hline$>2$ & 12 & 17.1 & 8 & 12.5 & & & 2 & 9.1 & 8 & 15.4 & & \\
\hline $\mathrm{Hb}(\mathrm{g} / \mathrm{dl})$ & & & & & & & & & & & u test & $P$ value \\
\hline BMI z score & & & & & & & & & & & $0.739^{*}$ & $0.481^{*}$ \\
\hline$<-2$ & 11.8 & $2.1^{*}$ & 11.3 & $3.6^{* *}$ & & & & & 11.9 & $1.9^{\# \#}$ & $0.139^{* *}$ & $0.327^{* *}$ \\
\hline$-2-2$ & 13.5 & \pm 4.9 & 13. & $=3.9$ & & & 14. & \pm 5.2 & 14.5 & \pm 4.2 & $0.138^{\#}$ & $0.715^{\#}$ \\
\hline$>2$ & 12.9 & \pm 4.1 & 12. & $=4.2$ & & & & \pm 0 & 13.2 & \pm 4.1 & $4.8^{\# \#}$ & $0.012^{\# \#}$ \\
\hline
\end{tabular}


Table (3): Comparison between the studied groups in terms of sociodemographic characteristics of children

\begin{tabular}{|c|c|c|c|c|c|}
\hline & \multicolumn{3}{|c|}{ BMI } & \multirow[t]{3}{*}{$\mathrm{X} 2$} & \multirow[t]{3}{*}{$P$ value } \\
\hline & $\begin{array}{c}\text { Low } \\
(\text { No=32) }\end{array}$ & $\begin{array}{l}\text { Normal } \\
\text { No }=146\end{array}$ & $\begin{array}{c}\text { Overweight } \\
\text { No }=30\end{array}$ & & \\
\hline & No.(\%) & No. $(\%)$ & No.(\%) & & \\
\hline $\begin{array}{l}\text { Residence } \\
\text { - Urban } \\
\text { - Rural }\end{array}$ & $\begin{array}{l}22(68.8) \\
10(31.3)\end{array}$ & $\begin{array}{c}124(84.9) \\
44(15.1)\end{array}$ & $\begin{array}{c}24(80) \\
6(20)\end{array}$ & 2.34 & 0.311 \\
\hline $\begin{array}{l}\text { Mothers education } \\
\text { - Illiterate / Read and write } \\
\text { - Below secondary } \\
\text { - Secondary } \\
\text { - Above secondary }\end{array}$ & $\begin{array}{c}4(6.3) \\
0(0) \\
4(12.5) \\
26(81.3)\end{array}$ & $\begin{array}{l}26(17.8) \\
16(11) \\
18(12.3) \\
86(58.9)\end{array}$ & $\begin{array}{c}2(6.7) \\
2(6.7) \\
0(0) \\
26(86.7)\end{array}$ & 7.8 & 0.255 \\
\hline $\begin{array}{l}\text { Mothers work } \\
\text { - No } \\
\text { - Yes }\end{array}$ & $\begin{array}{c}6(18.8) \\
26(81.3)\end{array}$ & $\begin{array}{l}70(47.9) \\
76(52.1)\end{array}$ & $\begin{array}{l}10(33.3) \\
20(66.7)\end{array}$ & 5.08 & 0.079 \\
\hline $\begin{array}{l}\text { Socioeconomic status } \\
\text { - Low } \\
\text { - Moderate } \\
\text { - High }\end{array}$ & $\begin{array}{c}16(50) \\
10(31.3) \\
6(18.8)\end{array}$ & $\begin{array}{l}10(6.8) \\
122(83.6) \\
12(9.6)\end{array}$ & $\begin{array}{c}4(13.3) \\
12(40) \\
14(46.7)\end{array}$ & 16.7 & 0.002 \\
\hline $\begin{array}{l}\text { Mother's weight at delivery } \\
\text { - Over to gestational age } \\
\text { - Normal to GA } \\
\text { - Under to GA }\end{array}$ & $\begin{array}{c}5(15.6) \\
12(37.5) \\
15(46.9)\end{array}$ & $\begin{array}{c}39(26.7) \\
93(63.7) \\
14(9.6)\end{array}$ & $\begin{array}{c}16(53.3) \\
9(30) \\
5(16.7)\end{array}$ & 37.9 & $<0.001$ \\
\hline $\begin{array}{l}\text { Family history of Genetic } \\
\text { Diseases } \\
\text { - Yes } \\
\text { - No }\end{array}$ & $\begin{array}{c}2(6.3) \\
30(93.8)\end{array}$ & $\begin{array}{c}6(4.1) \\
140(95.9)\end{array}$ & $\begin{array}{l}4(13.3) \\
26(86.7\end{array}$ & 1.95 & 0.376 \\
\hline
\end{tabular}




$$
\text { الملخص العربى }
$$

\title{
تقييم الحالة التغذوية للأطفال ذوي الاحتياجات الخاصة
}

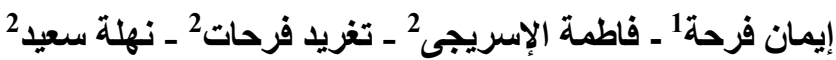

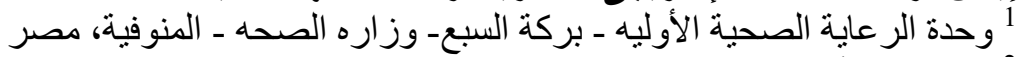

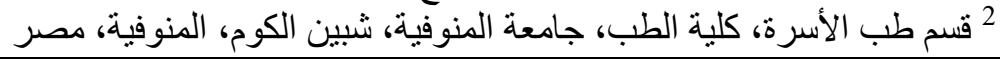

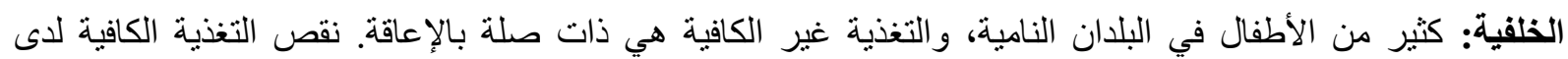

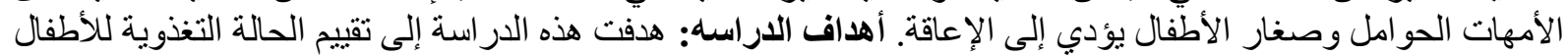

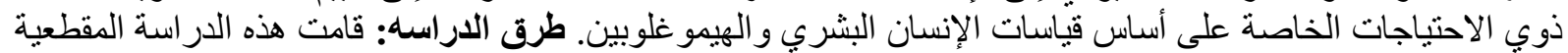

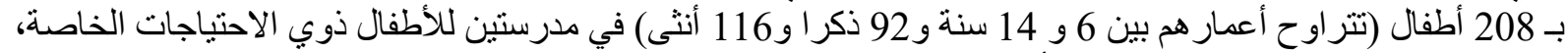

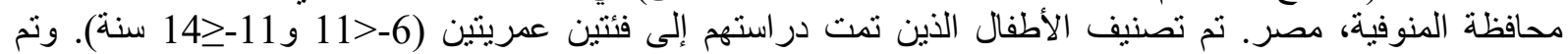

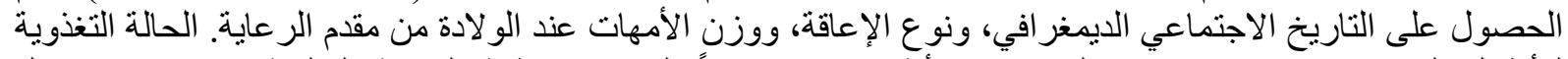

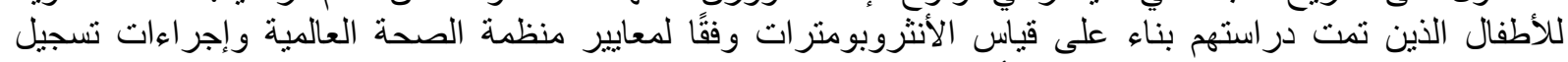

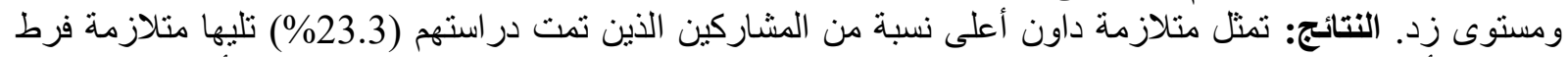
الحركة للأطفال (16.3\%).

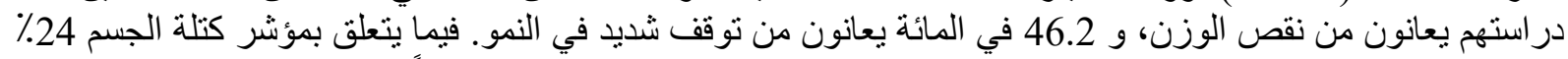

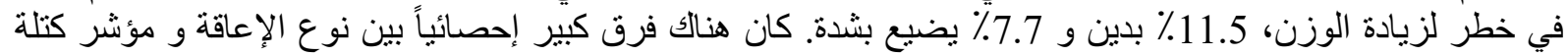

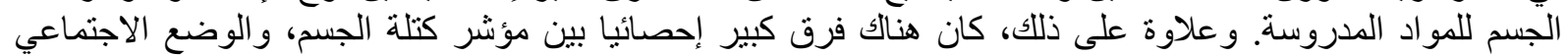

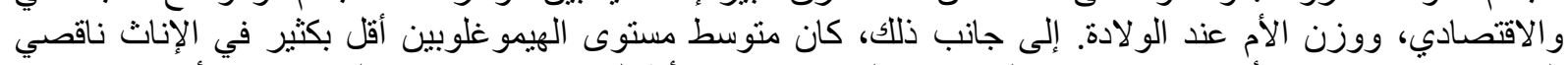

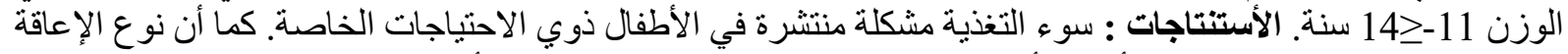

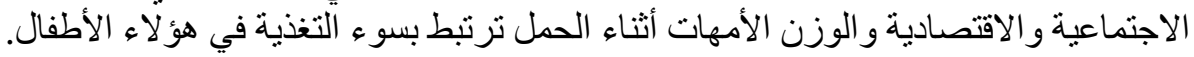

